\title{
Investment on Human Capital in a Dynamic Contest Model
}

\author{
Kerim Keskin* $\quad$ Çă̆rı Sağlam ${ }^{\dagger}$
}

\begin{abstract}
Although most contest games are modeled in such a way that the outcome depends only on the efforts exerted by the contestants, what is arguably more important is the contestants' effective efforts which may be influenced also by their ability, human capital, strength, etc. In this paper, we investigate an extensive model including such an effectiveness parameter and analyze the optimal investment behavior in a dynamic conflict framework. At each period, two contestants compete for a common prize by choosing contest efforts and investment levels. Each contestant's investment accumulates as his/her human capital which depreciates through time. Who wins the component contest at a particular period is determined by the contestants' effective efforts, defined as increasing functions of their efforts and human capitals. Following the analysis of subgame perfect Nash equilibrium in a two-period model and of open-loop equilibrium in an infinitehorizon model, we provide intuitive comparative static results.
\end{abstract}

JEL classification: C72, D74

Keywords: Contests, Dynamic contests, Investment, Effectiveness, Human capital

\section{Introduction}

Human capital is a measure of an individual's knowledge, talent, or other intangible resources that can be used to create economic value; and it is considered to be one of the key determinants of economic growth. Following the seminal works by Mincer (1958), Schultz (1961), and Becker (1962), there has emerged a vast literature on the theoretical and empirical investigation of human capital emergence, investment, and accumulation. This literature mostly concentrates on the relationships between human capital and growth (see Mankiw et al., 1992; Galor and Weil, 2000; Barro, 2001, among others), human capital and earnings (see Ben-Porath, 1967; Mincer, 1997; Huggett et al.,

*Kadir Has University. 34083 | İstanbul, Turkey. E-mail: kerim.keskin@khas.edu.tr

${ }^{\dagger}$ Bilkent University. 06800 | Ankara, Turkey. E-mail: csaglam@bilkent.edu.tr 
2006, among others), human capital and productivity (see Black and Lynch, 1996; Engelbrecht, 1997; Dearden et al., 2006, among others), and other relevant issues. In this paper, we also contribute to this literature by studying investment on human capital in a dynamic contest model.

A contest game is a strategic interaction in which each participant exerts irreversible and costly efforts to win a valuable prize. Perhaps the most common real-life examples are sports, warfare, firm competition, patent races, etc. ${ }^{1}$ Although most of these interactions can be modeled as a static game, there is also a bulk of literature concentrating on dynamic models (see Leininger and Yang, 1994; Gradstein, 1998; Gradstein and Konrad, 1999; Yildirim, 2005; Grossmann and Dietl, 2009; Konrad and Kovenock, 2009, among others). Such dynamic contest models allow for the analyses of several interesting concepts; such as the discouragement effect (see Konrad and Kovenock, 2009; Doğan et al., 2017), the effect of learning (see Clark and Nilssen, 2013), optimal contest design (see Gradstein, 1998; Gradstein and Konrad, 1999), adding to the previously exerted effort (see Yildirim, 2005), comparisons between the equilibrium behavior in static and dynamic models (see Leininger and Yang, 1994; Keskin and Sağlam, 2017), and investment decisions affecting future outcomes (see Fu and $\mathrm{Lu}, 2009$; Grossmann and Dietl, 2009).

In this paper, we are interested in a dynamic contest game where two participants [i] make costly investments which accumulate as their human capital and [ii] exert costly efforts to win a component contest in each period. For this model, we offer the following interpretation: Consider a dynamic competition between two individuals working in the same firm. A period ends with the firm owner giving a premium to one of these individuals. Each individual can invest in his/her education, which consequently improves his/her human capital in the following period. They also exert costly efforts to receive the premium; and the winner in a given period is determined by their effective efforts, defined as increasing functions of their contest efforts and human capitals. For instance, suppose that each individual chooses how much time to allocate in work, education, and leisure. ${ }^{2}$ If an individual allocates more time in work this period, then his/her chance of winning the current contest increases; but if an individual allocates more time in education this period, then his/her human capital in the following period improves, which in turn increases the chances of winning the contests in periods to come.

For a more concrete real-life example, consider two countries engaged in a dynamic market competition in a labor-intensive market (such as agriculture, tourism, etc.). A country's aim is to help its firms increase their market shares. The market share depends on the quality of the end-product, which is influenced by the productivity and amount of labor used in production. It is the product quality that determines a country's success in the component contest in a given period. Each country has an option to [i] invest in human capital (by improving the education system) to increase

\footnotetext{
${ }^{1}$ For detailed investigations of the works in the contest literature, see Corchón (2007); Konrad (2009); Dechenaux et al. (2015) among others.

${ }^{2}$ As a matter of fact, leisure choice is not explicitly modeled here, but it is captured in the cost of allocating time in work or education.
} 
future productivity and [ii] subsidize labor hiring to boost current production. The trade-off between these two options is in the center of our analysis. As a matter of fact, it is possible to motivate the productivity/effectiveness parameter in a different context other than human capital. Consider two countries engaged in a dynamic warfare, such that the effectiveness parameter is now labeled as military strength. Investment in military training and/or weapons technology improves the country's military strength; and in each period, the winner of the component contest is determined by the countries' effective efforts, defined as functions of their contest efforts and military strengths. ${ }^{3}$

We should mention that investment-type decisions are already incorporated in the dynamic contest literature; see Fu and Lu (2009); Grossmann and Dietl (2009); Grossmann et al. (2011); Bevia and Corchón (2013) for some examples. ${ }^{4}$ Broadly speaking, in all of these papers, an increase in the strategy chosen in period $t$ positively affects the outcome of the component contest in the following period $t+1$. In comparison to $\mathrm{Fu}$ and $\mathrm{Lu}$ (2009) and Bevia and Corchón (2013), we are interested in a different model which includes effectiveness accumulating through time. This is an important difference, since "accumulation" implies that the investment in period $t$ also indirectly affects the outcomes of all the contests throughout. In that regard, our model is much closer to the models studied by Grossmann and Dietl (2009) and Grossmann et al. (2011). However, we also differ from their models in the following sense. Rather than interpreting contest efforts as indirect investments, we consider two separate choice variables: effort and investment. This way, we distinguish between effort and investment decisions, thereby capturing a dynamic missing from the existing models. To the best of our knowledge, we are the first to investigate a two-choice-variable dynamic contest game with accumulating investments.

In the first part of the following section, we study a two-period version of this dynamic contest. We show in a subgame perfect Nash equilibrium that players exert the same equilibrium efforts independent of the asymmetry in their effectiveness levels in a given period. This implies that the ratio of winning probabilities is directly proportional to the ratio of effectiveness levels. Moreover, we find that the equilibrium investments depend on the asymmetry in the education efficiency. In the second part of the following section, we analyze open-loop equilibrium in an infinite-horizon version of the contest. Our findings indicate that the steady state efforts have similar characteristics with the

\footnotetext{
${ }^{3}$ Given this alternative interpretation, our work can also be seen as a theoretical contribution to the literature on military expenditures (see Rothschild, 1973; Deger and Smith, 1983; Kollias, 1996; Pieroni, 2009; Alptekin and Levine, 2012, among others). This literature mostly focuses on the amount of military investments and its effects on a country's economy (e.g., international trade, economic growth, etc.). To our knowledge, earlier works have not considered a dynamic game-theoretic model to investigate the strategic interaction that incentivizes the contending parties to invest in their military. Our model can fill this gap, since it provides a strategic framework to understand how countries can utilize their military expenditures against their rivals through time.

${ }^{4}$ There are other studies having a similar flavor, but they are quite different than the model studied here as they capture the effect of investment by a decrease in the cost of effort (see Münster, 2007; Clark and Nilssen, 2013). Furthermore, in a rather different investment-contest game, Amegashie (2011) shows that an asset owner might overinvest when property rights are incomplete.
} 
equilibrium efforts in the two-period version. Interestingly, the steady state investments turn out to be symmetric as well, independent of any asymmetry in the model, whereas the asymmetry in the education efficiency significantly affects the steady state human capitals. All these results highlight the importance of investment on human capital in dynamic conflict situations. ${ }^{5}$

The rest of the paper is organized as follows. In Section 2, we formulate the model structure and analyze equilibrium behavior in both finite- and infinite-horizon versions of the model. Section 3 concludes.

\section{The Model}

There are two players in a dynamic contest game. At each period $t=1,2, \ldots$, they participate in a component contest choosing a strategy $\left(e_{i, t}, s_{i, t}\right)$ where $e_{i, t}$ denotes the contest effort and $s_{i, t}$ denotes the investment. Each player $i$ 's effective effort in period $t$ is defined as an increasing function of $e_{i, t}$ and the effectiveness parameter $h_{i, t}$ (also referred to as human capital parameter). The effective efforts determine the outcome of the component contest in period $t$. The winner gets a common prize of $V>0$, whereas the loser gets a normalized payoff of 0 . Furthermore, player $i$ 's investment in period $t$ directly affects player $i$ 's effectiveness in period $t+1$, which accumulates over time. Due to accumulation, investment in period $t$ indirectly affects his/her effectiveness in all of the following periods $t^{\prime}>t$; and as a result, investment in period $t$ also indirectly affects player $i$ 's probability of winning the battle at any period $t^{\prime}>t$.

Given a list of actions

$$
\left(e_{j, t}, s_{j, t}\right)_{t=1,2, \ldots}
$$

for player $j$ and for all periods $t=1,2, \ldots$, we say that player $i$ maximizes

$$
\sum_{t=1,2, \ldots} \beta^{t-1}\left[p_{i}\left(e_{1, t}, h_{1, t}, e_{2, t}, h_{2, t}\right) V-c_{i}\left(e_{i, t}, s_{i, t}\right)\right]
$$

subject to

$$
h_{i, t+1}=(1-\delta) h_{i, t}+\varphi_{i}\left(s_{i, t}\right)
$$

given $h_{1,1}, h_{2,1}>0$.

In this context, $\beta \in(0,1)$ is the common discount factor; $\delta \in(0,1)$ is the common depreciation rate for effectiveness; $V>0$ is the common prize a player receives after winning a component contest; and for each player $i \in\{1,2\}, p_{i}\left(e_{1, t}, h_{1, t}, e_{2, t}, h_{2, t}\right)$ denotes the respective winning probability, $c_{i}\left(e_{i, t}, s_{i, t}\right)$ denotes the respective total cost of effort and investment, and $\varphi_{i}\left(s_{i, t}\right)$ denotes the respective influence of investment on the player's

\footnotetext{
${ }^{5}$ Grossmann et al. (2010) show that linear costs imply immediate convergence of the asset stocks to the steady state. Later, Grossmann et al. (2011) show that if the cost function is convex, then the speed of convergence significantly depends on the elasticity of the cost function. In contrast to these results, we find that even with linear cost functions, non-immediate convergence is possible such that the speed of convergence depends on multiple model parameters.
} 
effectiveness level in period $t+1$. We further assume that all functions are differentiable and for each player $i \in\{1,2\}$ :

$\diamond$ the contest success function $p_{i}$ is increasing in $e_{i, t}$ and $h_{i, t}$, but decreasing in $e_{j, t}$ and $h_{j, t}$;

$\diamond$ the cost function $c_{i}$ is increasing and convex in both arguments; and

$\diamond$ the effectiveness transformation function $\varphi_{i}$ is increasing and concave in its argument, and it satisfies $\lim _{s_{i, t} \rightarrow \infty} \varphi_{i}^{\prime}\left(s_{i, t}\right) \rightarrow 0$.

In the following subsections, we study equilibrium behavior in both finite- and infinite-horizon versions of this contest.

\section{$2.1 \quad$ Finite-horizon}

We consider a two-period model and analyze pure-strategy subgame perfect Nash equilibrium. For that we perform backward induction. In the second period, there will be no investment in the equilibrium: $s_{1,2}^{*}=s_{2,2}^{*}=0$. Therefore, each player only determines his/her effort level in period 2. Given $e_{j, 2}$, the optimal solution satisfies the following first order condition for player $i \in\{1,2\}$ :

$$
\frac{\partial p_{i}\left(e_{1,2}, h_{1,2}, e_{2,2}, h_{2,2}\right)}{\partial e_{i, 2}} V-\frac{\partial c_{i}\left(e_{i, 2}, 0\right)}{\partial e_{i, 2}}=0
$$

Whenever they exist, the equilibrium efforts $\left(e_{1,2}^{*}, e_{2,2}^{*}\right)$ are implicitly characterized by this system of equations, (1).

Knowing these equilibrium efforts in the second period, we can proceed to period 1. Given $e_{j, 1}$ and $s_{j, 1}$, the first order condition with respect to $e_{i, 1}$ for player $i \in\{1,2\}$ :

$$
\frac{\partial p_{i}\left(e_{1,1}, h_{1,1}, e_{2,1}, h_{2,1}\right)}{\partial e_{i, 1}} V-\frac{\partial c_{i}\left(e_{i, 1}, s_{i, 1}\right)}{\partial e_{i, 1}}=0
$$

Given $e_{j, 1}$ and $s_{j, 1}$, the first order condition with respect to $s_{i, 1}$ for player $i \in\{1,2\}$ :

$$
\begin{aligned}
\frac{\partial \varphi_{i}\left(s_{i, 1}\right)}{\partial s_{i, 1}} & \left(\frac{\partial p_{i}\left(e_{1,2}^{*}, h_{1,2}, e_{2,2}^{*}, h_{2,2}\right)}{\partial e_{i, 2}^{*}} \frac{\partial e_{i, 2}^{*}}{\partial h_{i, 2}} V+\frac{\partial p_{i}\left(e_{1,2}^{*}, h_{1,2}, e_{2,2}^{*}, h_{2,2}\right)}{\partial h_{i, 2}} V\right. \\
& \left.+\frac{\partial p_{i}\left(e_{1,2}^{*}, h_{1,2}, e_{2,2}^{*}, h_{2,2}\right)}{\partial e_{j, 2}^{*}} \frac{\partial e_{j, 2}^{*}}{\partial h_{i, 2}} V-\frac{\partial c_{i}\left(e_{i, 2}^{*}, 0\right)}{\partial e_{i, 2}^{*}} \frac{\partial e_{i, 2}^{*}}{\partial h_{i, 2}}\right)=\frac{1}{\beta} \frac{\partial c_{i}\left(e_{i, 1}, s_{i, 1}\right)}{\partial s_{i, 1}} .
\end{aligned}
$$

Whenever they exist, the equilibrium efforts $\left(e_{1,1}^{*}, e_{2,1}^{*}\right)$ and investments $\left(s_{1,1}^{*}, s_{2,1}^{*}\right)$ for both players are implicitly characterized by this system of equations: (2)-(3). For concreteness, suppose that the cost function is additively separable. Then for any player $i \in\{1,2\}$, the first order condition (2) becomes independent of $s_{i, 1}$, so that the equilibrium efforts $\left(e_{1,1}^{*}, e_{2,1}^{*}\right)$ can directly be derived using only these first order conditions. And given the equilibrium efforts in both periods, the equilibrium investments $\left(s_{1,1}^{*}, s_{2,1}^{*}\right)$ 
are those that solve the first order conditions with respect to $s_{i, 1}$. On the other hand, if the cost function is not additively separable, then all of these four first order conditions should be solved simultaneously.

Now, in order to have more concrete ideas about the subgame perfect Nash equilibrium of this model, we utilize specific functional forms for $p_{i}, \varphi_{i}$, and $c_{i}$. In particular, we consider the following Tullock-type contest success function $p_{i}{ }^{6}$

$$
p_{i}\left(e_{1, t}, h_{1, t}, e_{2, t}, h_{2, t}\right)=\frac{h_{i, t} e_{i, t}}{h_{1, t} e_{1, t}+h_{2, t} e_{2, t}}
$$

and the following effectiveness transformation function $\varphi_{i}$ :

$$
\varphi_{i}\left(s_{i, t}\right)=\gamma_{i} s_{i, t}^{\alpha}
$$

where $\alpha \in(0,1)$ represents the curvature and captures diminishing marginal returns of investment, and $\gamma_{i} \geq 1$ regulates the asymmetric rate of increase indicating the efficiency of the education system. We also consider an additively separable, linear cost function $c_{i}$ :

$$
c_{i}\left(e_{i, t}, s_{i, t}\right)=e_{i, t}+s_{i, t}
$$

The equilibrium strategies are summarized in the following proposition.

Proposition 1. In the two-period dynamic contest game above, the equilibrium investments in period 2 are $s_{1,2}^{*}=s_{2,2}^{*}=0$. The equilibrium efforts are given by

$$
e_{1,1}^{*}=e_{2,1}^{*}=\frac{h_{1,1} h_{2,1} V}{\left(h_{1,1}+h_{2,1}\right)^{2}} \quad \text { and } \quad e_{1,2}^{*}=e_{2,2}^{*}=\frac{h_{1,2} h_{2,2} V}{\left(h_{1,2}+h_{2,2}\right)^{2}} \text {. }
$$

Moreover, for player $i \in\{1,2\}$, the equilibrium investment level in period 1 is implicitly characterized by

$$
s_{i, 1}^{* 1-\alpha}=2 \alpha \beta \gamma_{i} V \frac{\left[(1-\delta) h_{i, 1}+\gamma_{i} s_{i, 1}^{*} \alpha\right] \cdot\left[(1-\delta) h_{j, 1}+\gamma_{j}\left(\frac{\gamma_{j}}{\gamma_{i}}\right)^{\frac{\alpha}{1-\alpha}} s_{i, 1}^{* \alpha}\right]}{\left[(1-\delta)\left(h_{i, 1}+h_{j, 1}\right)+\gamma_{i} s_{i, 1}^{*}{ }^{\alpha}+\gamma_{j}\left(\frac{\gamma_{j}}{\gamma_{i}}\right)^{\frac{\alpha}{1-\alpha}} s_{i, 1}^{*}\right]^{3}} \text { for } j \neq i \text {. }
$$

The equilibrium analysis is provided below. Once again, we already know that $s_{1,2}^{*}=s_{2,2}^{*}=0$. Consider player 1's effort decision in period 2. The respective first order condition (1) becomes

$$
\frac{h_{1,2} h_{2,2} e_{2,2}}{\left(h_{1,2} e_{1,2}+h_{2,2} e_{2,2}\right)^{2}} V-1=0 .
$$

\footnotetext{
${ }^{6}$ Clark and Riis (1998) argue that this contest success function becomes particularly useful when winning probabilities depend on personal characteristics of the contestants. In the current context, the effectiveness parameter $h_{i, t}$ represents a personal characteristic. The interested reader is referred to Clark and Riis (1998) for an axiomatization.
} 
Considering the symmetric first order condition for player 2, we have the following best response functions:

$$
e_{1,2}^{*}=\frac{\sqrt{h_{1,2} h_{2,2} e_{2,2}^{*} V}-h_{2,2} e_{2,2}^{*}}{h_{1,2}} \quad \text { and } \quad e_{2,2}^{*}=\frac{\sqrt{h_{1,2} h_{2,2} e_{1,2}^{*} V}-h_{1,2} e_{1,2}^{*}}{h_{2,2}} .
$$

This yields the following equilibrium effort strategies for players 1 and 2:

$$
e_{1,2}^{*}=e_{2,2}^{*}=\frac{h_{1,2} h_{2,2} V}{\left(h_{1,2}+h_{2,2}\right)^{2}} .
$$

We now proceed to period 1 . In a similar manner, the first order condition with respect to $e_{1,1}$ becomes

$$
\frac{h_{1,1} h_{2,1} e_{2,1}}{\left(h_{1,1} e_{1,1}+h_{2,1} e_{2,1}\right)^{2}} V-1=0 .
$$

Considering the symmetric first order condition for player 2 , we find the equilibrium effort strategies for players 1 and 2 to be

$$
e_{1,1}^{*}=e_{2,1}^{*}=\frac{h_{1,1} h_{2,1} V}{\left(h_{1,1}+h_{2,1}\right)^{2}} .
$$

In both periods, both players' equilibrium efforts increase in the winning prize $V$. Moreover, for any $t \in\{1,2\}$, if $h_{i, t}>h_{j, t}$, then both $e_{i, t}^{*}$ and $e_{j, t}^{*}$ decrease in $h_{i, t}$ and increase in $h_{j, t}$. This implies that as the distance between the effectiveness parameters increases/decreases, the component contest becomes less/more competitive, so that the equilibrium efforts decrease/increase. In case $h_{i, t}=h_{j, t}$ for some $t \in\{1,2\}$, the equilibrium efforts $e_{i, t}^{*}$ and $e_{j, t}^{*}$ become independent of the effectiveness parameters.

We further observe that $e_{1,1}^{*}=e_{2,1}^{*}$ and $e_{1,2}^{*}=e_{2,2}^{*}$. This means that the ratio of equilibrium efforts do not depend on the ratio of effectiveness parameters. More precisely, even when $h_{i, t}>h_{j, t}$ for $i \neq j$, both players exert the same amount of effort in period $t$. Accordingly, the one with a higher effectiveness parameter would always have a higher probability of winning at the equilibrium. Hence, not so surprisingly, being more effective turns out to be extremely important, which further highlights the importance of investment decisions.

Finally, the first order condition with respect to $s_{1,1}$ becomes

$$
\begin{array}{r}
\alpha \gamma_{1} s_{1,1}{ }^{\alpha-1}\left(\frac{h_{1,2} h_{2,2} e_{2,2}^{*}}{\left(h_{1,2} e_{1,2}^{*}+h_{2,2} e_{2,2}^{*}\right)^{2}} \frac{h_{2,2}\left(h_{2,2}-h_{1,2}\right)}{\left(h_{1,2}+h_{2,2}\right)^{3}} V^{2}\right. \\
+\frac{h_{2,2} e_{1,2}^{*} e_{2,2}^{*}}{\left(h_{1,2} e_{1,2}^{*}+h_{2,2} e_{2,2}^{*}\right)^{2}} V-\frac{h_{1,2} h_{2,2} e_{1,2}^{*}}{\left(h_{1,2} e_{1,2}^{*}+h_{2,2} e_{2,2}^{*}\right)^{2}} \frac{h_{2,2}\left(h_{2,2}-h_{1,2}\right)}{\left(h_{1,2}+h_{2,2}\right)^{3}} V^{2} \\
\left.\quad-\frac{h_{2,2}\left(h_{2,2}-h_{1,2}\right)}{\left(h_{1,2}+h_{2,2}\right)^{3}} V\right)=\frac{1}{\beta} .
\end{array}
$$

Writing $e_{1,2}^{*}$, and $e_{2,2}^{*}$ explicitly, we have

$$
s_{1,1}^{\alpha-1} \frac{2 h_{1,2} h_{2,2} V}{\left(h_{1,2}+h_{2,2}\right)^{3}}=\frac{1}{\alpha \beta \gamma_{1}} .
$$


Considering the symmetric first order condition with respect to $s_{2,1}$ and dividing them side-by-side:

$$
\frac{s_{1,1}^{*}}{s_{2,1}^{*}}=\left(\frac{\gamma_{1}}{\gamma_{2}}\right)^{\frac{1}{1-\alpha}} .
$$

Therefore, the ratio of equilibrium investments depends only on $\alpha$ and $\gamma_{i}$ 's. To be more precise, no matter what $h_{1,1}$ and $h_{2,1}$ are, the player with a higher $\gamma$ invests more in the equilibrium. On top of that, the difference between $\gamma_{i}$ 's becomes more important as $\alpha$ increases.

Using equation (14) in equation (13), we obtain

$$
s_{1,1}^{*}{ }^{1-\alpha}=2 \alpha \beta \gamma_{1} V \frac{\left[(1-\delta) h_{1,1}+\gamma_{1} s_{1,1}^{*} \alpha\right] \cdot\left[(1-\delta) h_{2,1}+\gamma_{2}\left(\frac{\gamma_{2}}{\gamma_{1}}\right)^{\frac{\alpha}{1-\alpha}} s_{1,1}^{* \alpha}\right]}{\left[(1-\delta)\left(h_{1,1}+h_{2,1}\right)+\gamma_{1} s_{1,1}^{*}{ }^{\alpha}+\gamma_{2}\left(\frac{\gamma_{2}}{\gamma_{1}}\right)^{\frac{\alpha}{1-\alpha}} s_{1,1}^{*}\right]^{3}} .
$$

This equation implicitly characterizes the equilibrium investment level for player $1 .{ }^{7}$ And player 2's equilibrium investment is characterized by a symmetric equation. Unfortunately, these equations are too complicated to be solved further. Accordingly, we analyze the extreme case $\delta=1$ in order to have some understanding of the equilibrium strategies in closed form. Then we return to the general case, consider some numerical values for model parameters, and provide the best response graphs using equation (13) and its symmetric version.

For now, let $\delta=1$. Then equation (15) and its symmetric version yield

$$
s_{1,1}^{*}=\frac{2 \alpha \beta \gamma_{1}^{\frac{2}{1-\alpha}} \gamma_{2}^{\frac{1}{1-\alpha}} V}{\left(\gamma_{1}^{\frac{1}{1-\alpha}}+\gamma_{2}^{\frac{1}{1-\alpha}}\right)^{3}} \quad \text { and } \quad s_{2,1}^{*}=\frac{2 \alpha \beta \gamma_{1}^{\frac{1}{1-\alpha}} \gamma_{2}^{\frac{2}{1-\alpha}} V}{\left(\gamma_{1}^{\frac{1}{1-\alpha}}+\gamma_{2}^{\frac{1}{1-\alpha}}\right)^{3}} \text {. }
$$

In this extreme case, both equilibrium investments increase in $\beta$ and $V$, which seem to have straightforward intuitions. Moreover, when $\gamma_{1} \neq \gamma_{2}, s_{i, 1}^{*}$ is increasing in $\gamma_{i}$ and decreasing in $\gamma_{j}$ if and only if $\gamma_{i} / \gamma_{j}<2^{1-\alpha}$. This inequality is surely satisfied when $\gamma_{j}>\gamma_{i}$; however, when $\gamma_{i}>\gamma_{j}$, it is satisfied only for sufficiently small values of $\alpha$ and $\gamma_{i}$. In case $\gamma_{1}=\gamma_{2}$, however, $s_{1,1}^{*}=s_{2,1}^{*}$ turns out to be independent of $\gamma_{i}$ 's.

For the case in which $\delta<1$, we provide a numerical analysis below. Assume that $\delta=0.25, \alpha=0.5, \beta=0.95$, and $V=4$. We further fix $h_{2,1}=2$ and $\gamma_{2}=2$, and we consider $h_{1,1} \in\{2,4\}$ and $\gamma_{1} \in\{1,2\}$ to investigate several asymmetric cases.

\section{[Figure 1]}

As seen in Figure 1, under symmetry, i.e., when $h_{1,1}=2$ and $\gamma_{1}=2$, the best response functions are symmetric, which leads to symmetric equilibrium investments:

\footnotetext{
${ }^{7}$ Calculating the limit values of both sides, one can verify that a positive solution exists.
} 
0.1677. When $h_{1,1}$ increases to 4 , the best response functions cease to be symmetric; but since $\gamma_{1}=\gamma_{2}$, the equilibrium investments are still symmetric: 0.0953. For this particular example, we observe a decrease in the equilibrium investments as $h_{1,1}$ becomes greater than $h_{2,1}$. The interpretation provided for the equilibrium efforts also applies here: when the distance between the initial effectiveness parameters increases, the component contest becomes less competitive, so that the equilibrium investments decrease. Moreover, given that $\gamma_{1}=\gamma_{2}$ and that players make the same amount of investments at the equilibrium, we see that $h_{1,2}>h_{2,2}$ in the second period. Following this observation, we can conjecture that for any $T$-period game in which $\gamma_{1}=\gamma_{2}$, the initially disadvantaged player can never catch up with the initially advantaged player.

In the remaining numerical examples, we consider two cases in which $\gamma_{1}=1$. We observe that Player 2 invests more at the equilibrium than player 1 does. More precisely, the equilibrium investments are given by $(0.1216,0.4864)$ when $h_{1,1}=2$ and by $(0.0294,0.1175)$ when $h_{1,1}=4$. Once again, we observe a substantial decrease in the equilibrium investments for both players once there is an increase in the initial human capital $h_{1,1}$. We further see that if $\gamma_{1}$ decreases while $h_{1,1}$ is kept constant, then the equilibrium investment for player 1 decreases, whereas the same for player 2 increases. Finally, in case $h_{1,1}=2$ and $\gamma_{1}=1$, we have $h_{1,2}<h_{2,2}$, meaning that player 2 gains an advantage over player 1 in the second period as he/she becomes more effective than player 1 ; however, when $h_{1,1}=4$ and $\gamma_{1}=1$, although player 2 is able to decrease the gap between their effectiveness parameters, player 1 remains to be the advantaged player in the second period. At this point, we can present another conjecture: If the contest has sufficiently many number of periods, then the initially disadvantaged player can eventually catch up with the initially advantaged player, if there exists asymmetry in $\gamma_{i}^{\prime}$ 's in favor of the former.

\section{$2.2 \quad$ Infinite-horizon}

We consider an infinite-horizon model. Assuming that a player's effort and investment decisions are not observable to his/her competitor, we resort to open-loop strategies and analyze pure-strategy open-loop equilibrium. Accordingly, each player chooses an action path in the first period and commits to these strategies throughout the game. Taking a pre-committed action path $\left(\mathbf{e}_{j}, \mathbf{s}_{j}\right)=\left(e_{j, t}, s_{j, t}\right)_{t=1}^{\infty}$ for player $j$ as given, player $i \in\{1,2\}$ determines his/her best responses aiming to maximize his/her expected utility in the whole game. ${ }^{8}$

To analyze open-loop equilibrium, we first define a value function for each player $i \in\{1,2\}$ :

$$
\mathcal{V}\left(h_{i, 1} \mid\left\{h_{j, 1},\left(\mathbf{e}_{j}, \mathbf{s}_{j}\right)\right\}\right)=\max _{\mathbf{e}_{i}, \mathbf{s}_{i}} \sum_{t=1}^{\infty} \beta^{t-1}\left[p_{i}\left(e_{1, t}, h_{1, t}, e_{2, t}, h_{2, t}\right) V-c_{i}\left(e_{i, t}, s_{i, t}\right)\right]
$$

\footnotetext{
${ }^{8} \mathrm{~A}$ technical reason of analyzing open-loop equilibrium is tractability. Recently, in two related studies, Grossmann et al. (2010) and Grossmann et al. (2011) also resort to open-loop strategies, suffering from similar technical difficulties.
} 
where $i \neq j$. The bounds on discounting and the limit condition on the effectiveness transformation function guarantee a finite value function. Under our assumptions, it can also be shown that the value function $\mathcal{V}$ is non-negative and continuous (see Stokey and Lucas, 1989; Le Van and Dana, 2003, among others). Given these observations, the associated Bellman equation for each player $i \in\{1,2\}$ can be written as:

$$
\begin{aligned}
\mathcal{V}\left(h_{i, t}\right)= & \max _{e_{i, t}, s_{i, t}}\left\{p_{i}\left(e_{1, t}, h_{1, t}, e_{2, t}, h_{2, t}\right) V-c_{i}\left(e_{i, t}, s_{i, t}\right)+\beta \cdot \mathcal{V}\left(h_{i, t+1}\right)\right\} \\
& \text { subject to } \quad h_{i, t+1}=(1-\delta) h_{i, t}+\varphi_{i}\left(s_{i, t}\right)
\end{aligned}
$$

given $h_{i, 1}, h_{j, 1}>0$ and $\left(e_{j, t}, s_{j, t}\right)_{t=1}^{\infty}$ where $i \neq j$. This gives the following Lagrangian function for player $i \in\{1,2\}$ :

$$
\mathscr{L}_{i}=\mathcal{V}\left(h_{i, t}\right)+\lambda_{t} \cdot\left[(1-\delta) h_{i, t}+\varphi_{i}\left(s_{i, t}\right)-h_{i, t+1}\right]
$$

which is to be maximized with respect to $e_{i, t}, s_{i, t}, h_{i, t+1}$, and $\lambda_{t}$.

The respective first order conditions for optimality are

$$
\begin{gathered}
\frac{\partial p_{i}\left(e_{1, t}, h_{1, t}, e_{2, t}, h_{2, t}\right)}{\partial e_{i, t}} V=\frac{\partial c_{i}\left(e_{i, t}, s_{i, t}\right)}{\partial e_{i, t}} ; \\
\lambda_{t} \frac{\partial \varphi_{i}\left(s_{i, t}\right)}{\partial s_{i, t}}=\frac{\partial c_{i}\left(e_{i, t}, s_{i, t}\right)}{\partial s_{i, t}} ; \\
\beta \cdot \mathcal{V}^{\prime}\left(h_{i, t+1}\right)=\lambda_{t} ;
\end{gathered}
$$

and

$$
h_{i, t+1}=(1-\delta) h_{i, t}+\varphi_{i}\left(s_{i, t}\right) .
$$

Notice that the first order condition (20) is similar to the first order conditions (1) and (2) in the two-period version. This indicates that the equilibrium efforts are similar in nature for both finite- and infinite-horizon versions of the game. By contrast, the first order conditions (21) and (22) are different than their two-period version counterpart. In that regard, it would not be unreasonable to expect some differences in the equilibrium investment levels.

The envelope condition can be written as

$$
\mathcal{V}^{\prime}\left(h_{i, t}\right)=\frac{\partial p_{i}\left(e_{1, t}, h_{1, t}, e_{2, t}, h_{2, t}\right)}{\partial h_{i, t}} V+(1-\delta) \lambda_{t} .
$$

From equations (22) and (24), we obtain

$$
\beta\left(\frac{\partial p_{i}\left(e_{1, t+1}, h_{1, t+1}, e_{2, t+1}, h_{2, t+1}\right)}{\partial h_{i, t+1}} V+(1-\delta) \lambda_{t+1}\right)=\lambda_{t}
$$

which is used in the derivation of the following Euler equation:

$$
\frac{\partial p_{i}\left(e_{1, t+1}, h_{1, t+1}, e_{2, t+1}, h_{2, t+1}\right)}{\partial h_{i, t+1}} \beta V=\frac{\frac{\partial c_{i}\left(e_{i, t}, s_{i, t}\right)}{\partial s_{i, t}}}{\frac{\partial \varphi_{i}\left(s_{i, t}\right)}{\partial s_{i, t}}}-\beta(1-\delta) \frac{\frac{\partial c_{i}\left(e_{i, t+1}, s_{i, t+1}\right)}{\partial s_{i, t+1}}}{\frac{\partial \varphi_{i}\left(s_{i, t+1}\right)}{\partial s_{i, t+1}}} .
$$


Whenever they exist, the equilibrium efforts and investments for player $i \in\{1,2\}$ are implicitly characterized by equations (20), (23), and (26).

In order to have more concrete ideas about the open-loop equilibrium of this model, we utilize the same functional forms used in the finite-horizon model. Doing that, we also intend to compare our findings for finite- and infinite-horizon versions. In particular, we consider the following Tullock-type contest success function $p_{i}$ :

$$
p_{i}\left(e_{1, t}, h_{1, t}, e_{2, t}, h_{2, t}\right)=\frac{h_{i, t} e_{i, t}}{h_{1, t} e_{1, t}+h_{2, t} e_{2, t}}
$$

and the following effectiveness transformation function $\varphi_{i}$ :

$$
\varphi_{i}\left(s_{i, t}\right)=\gamma_{i} s_{i, t}^{\alpha}
$$

where $\alpha \in(0,1)$ and $\gamma_{i} \geq 1$. We also consider the following cost function $c_{i}$ :

$$
c_{i}\left(e_{i, t}, s_{i, t}\right)=e_{i, t}+s_{i, t}
$$

The steady state values are summarized in the following proposition.

Proposition 2. In the infinite-horizon dynamic contest game above, the unique steady state is characterized by

$$
\begin{array}{r}
e_{1}=e_{2}=\frac{\gamma_{i} \gamma_{j} V}{\left(\gamma_{i}+\gamma_{j}\right)^{2}} ; \quad s_{1}=s_{2}=\frac{\alpha \beta \delta \gamma_{1} \gamma_{2} V}{\left(\gamma_{1}+\gamma_{2}\right)^{2}(1-\beta(1-\delta))} ; \\
\text { and } h_{i}=\frac{\gamma_{i}}{\delta} s^{\alpha} \quad \text { for every } i \in\{1,2\}
\end{array}
$$

The equilibrium analysis is provided below. For each player $i \in\{1,2\}$, directly incorporating the specified functions (4), (5), and (6) into the first order conditions (20), (23) and the Euler equation (26), we have

$$
\begin{gathered}
\frac{h_{1, t} h_{2, t} e_{j, t}}{\left(h_{1, t} e_{1, t}+h_{2, t} e_{2, t}\right)^{2}} V=1 \quad \text { for } j \neq i ; \\
h_{i, t+1}=(1-\delta) h_{i, t}+\gamma_{i} s_{i, t}{ }^{\alpha} ;
\end{gathered}
$$

and

$$
\frac{e_{1, t+1} h_{j, t+1} e_{2, t+1}}{\left(h_{1, t+1} e_{1, t+1}+h_{2, t+1} e_{2, t+1}\right)^{2}} \beta V=\frac{s_{i, t}^{1-\alpha}-\beta(1-\delta) s_{i, t+1}^{1-\alpha}}{\alpha \gamma_{i}} \text { for } j \neq i
$$

Using equation $\left(20^{\prime}\right)$ and its symmetric version for player $j$, we can see that

$$
\forall t: \quad e_{i, t}=e_{j, t}=e_{t}
$$


Then we proceed to the steady state analysis. Denoting the steady state values by dropping $t$ from the corresponding variables, we can write that the steady state value for effort is

$$
e_{i}=e_{j}=e=\frac{h_{i} h_{j} V}{\left(h_{i}+h_{j}\right)^{2}} .
$$

This finding is consistent with our aforementioned observation that the equilibrium efforts in finite- and infinite-horizon models are similar in nature. The steady state value for effort increases in the winning prize $V$. Moreover, given that $h_{i}>h_{j}$, the steady state value decreases in $h_{i}$, but increases in $h_{j}$. This implies that as the distance between the steady state values for effectiveness increases/decreases, the component contest becomes less/more competitive, so that the steady state efforts decrease/increase. Moreover, when $h_{i}=h_{j}$, the steady state $e$ turns out to be independent of $\gamma_{i}$. These findings are exactly the same with those for the equilibrium efforts in the two-period model.

The steady state values also satisfy

$$
\delta h_{i}=\gamma_{i} s_{i}^{\alpha}
$$

and

$$
\frac{h_{j}}{\left(h_{1}+h_{2}\right)^{2}} \beta V=\frac{(1-\beta(1-\delta)) s_{i}{ }^{1-\alpha}}{\alpha \gamma_{i}} \text { for } j \neq i
$$

for every $i \in\{1,2\}$. Using equation (23ss) and its symmetric version for player $j$, we obtain

$$
\frac{h_{i}}{h_{j}}=\frac{\gamma_{i}}{\gamma_{j}}\left(\frac{s_{i}}{s_{j}}\right)^{\alpha} .
$$

Using equation (26ss) and its symmetric version for player $j$, we further obtain

$$
\frac{h_{i}}{h_{j}}=\frac{\gamma_{i}}{\gamma_{j}}\left(\frac{s_{j}}{s_{i}}\right)^{1-\alpha} .
$$

These equations jointly imply that

$$
s_{i}=s_{j}=s \quad \text { and } \quad \frac{h_{i}}{h_{j}}=\frac{\gamma_{i}}{\gamma_{j}} .
$$

This finding is in stark contrast to our results in the two-period model. Previously, independent of the initial effectiveness parameters, the equilibrium investments were equal to each other only when $\gamma_{1}=\gamma_{2}$. On the other hand, at the steady state of the infinite-horizon model, it turns out that players always make the same steady state investments. Instead, the ratio of $\gamma_{i}$ 's governs the relationship between the steady state values for human capital. Independent of the initial effectiveness parameters, the player with a higher return to education ends up being more advantaged at the steady state.

Then using equation (23ss) once again, for every $i \in\{1,2\}$ :

$$
h_{i}=\frac{\gamma_{i}}{\delta} s^{\alpha}
$$


and substituting this into equation (12ss):

$$
s=\frac{\alpha \beta \delta \gamma_{1} \gamma_{2} V}{\left(\gamma_{1}+\gamma_{2}\right)^{2}(1-\beta(1-\delta))}
$$

Finally, we can further write that the steady state effort is

$$
e=\frac{\gamma_{i} \gamma_{j} V}{\left(\gamma_{i}+\gamma_{j}\right)^{2}}
$$

Our equilibrium analysis reveals that the steady state exists and is unique. The stability analysis is relegated to the Appendix. There we prove that the steady state cannot be a "source"; so that, it is either "saddle-path stable" or a "sink" depending on the values of model parameters. For instance, there exists a critical value for the winning prize above which a multiplicity of equilibrium paths emerges. The dynamics of the system around the unique steady state exhibits local indeterminacy if $V<V_{C}$ where

$$
V_{C}=\frac{\left(\gamma_{1}+\gamma_{2}\right)^{2}}{\gamma_{1} \gamma_{2}} \frac{(1-\beta(1-\delta))}{\alpha \beta \delta}\left(\frac{(1-\alpha) \beta(1-\delta)}{1-\alpha \beta(1-\delta)}\right)^{\frac{1-\alpha}{\alpha^{2}}}
$$

Moreover, when $V>V_{C}$, the unique steady state turns out to be saddle-path stable. To provide a further understanding of our model, we carry out a similar analysis using another bifurcation parameter. More precisely, rather than $V$, we choose $\gamma_{1}$ as the bifurcation parameter, after normalizing $\gamma_{2}=1$. There exist two critical values $\gamma_{1}^{-}$ and $\gamma_{1}^{+}$such that the unique steady state is saddle-path stable when $\gamma_{1}^{-}<\gamma_{1}<\gamma_{1}^{+}$. Otherwise, we observe local indeterminacy. These critical values are given by

$$
\gamma_{1}^{+}=\frac{1+\sqrt{1-\frac{4(1+\beta(1-\delta))\left(\frac{(1-\alpha) \beta(1-\delta)}{1-\alpha \beta(1-\delta)}\right)^{\frac{1-\alpha}{\alpha^{2}}}}{\alpha \beta \delta V}}}{1-\sqrt{1-\frac{4(1+\beta(1-\delta))\left(\frac{(1-\alpha) \beta(1-\delta)}{1-\alpha \beta(1-\delta)}\right)^{\frac{1-\alpha}{\alpha^{2}}}}{\alpha \beta \delta V}}} \text { and } \gamma_{1}^{-}=\frac{1-\sqrt{1-\frac{4(1+\beta(1-\delta))\left(\frac{(1-\alpha) \beta(1-\delta)}{1-\alpha \beta(1-\delta)}\right)^{\frac{1-\alpha}{\alpha^{2}}}}{\alpha \beta \delta V}}}{1+\sqrt{1-\frac{4(1+\beta(1-\delta))\left(\frac{(1-\alpha) \beta(1-\delta)}{1-\alpha \beta(1-\delta)}\right)^{\frac{1-\alpha}{\alpha^{2}}}}{\alpha \beta \delta V}}}
$$

Notice that $\gamma_{1}^{+}=1 / \gamma_{1}^{-}$. This further implies that the unique steady state turns out to be saddle-path stable if the asymmetry between players' effectiveness parameters is sufficiently low. However, when one of the players is too dominant in terms of effectiveness, the unique steady state exhibits local indeterminacy.

For the stable steady state, the following comparative static results apply. Noting that the comparative statics for the steady state efforts is already provided above, we now concentrate on the comparative statics for $s$ and $h_{i}$ 's. The steady state value for investment $s$ increases in $\beta$ and $V$, which seem to have straightforward intuitions. It is also increasing in $\alpha$ and $\delta$. Intuitively, an increase in $\alpha$ enhances the effect of the effectiveness transformation function so that players are more motivated to invest; and an increase in $\delta$ decreases the amount of human capital after depreciation so that players need to invest more to cover for that loss. When $\gamma_{i}>\gamma_{j}$, the investment $s$ decreases in $\gamma_{i}$, but increases in $\gamma_{j}$. This implies that as the distance between $\gamma_{i}$ 's increases/decreases, 
the steady state investment decreases/increases. Moreover, if $\gamma_{i}=\gamma_{j}$, then $s$ turns out to be independent of $\gamma_{i}$. Recalling our findings on the equilibrium investments in the two-period model, we see that both models have similar interpretations. ${ }^{9}$

The steady state value for effectiveness $h_{i}$ is an increasing and concave function of the steady state investment $s$. The direct implication is that $h_{i}$ preserves the same comparative statics results and interpretations with $s$ for the parameters $\alpha, \beta, \gamma_{j}$, and $V$. On top of that, $h_{i}$ is decreasing in $\delta$ and increasing in $\gamma_{i}$. The former shows that as the depreciation rate for human capital increases, the economy ends up at a lower level of human capital; and the latter indicates that as investment has a higher return, the economy stabilizes at a higher level of human capital.

\section{Conclusion}

In this paper we have studied a bilateral dynamic conflict in which both individuals make two choices at each period: effort and investment. Investment in period $t$ improves effectiveness (i.e., human capital) in the next period, which also accumulates through time; and contest effort and human capital in period $t$ jointly determine the individual's probability of winning the component contest in period $t$. This way, we distinguish between effort and investment decisions, thereby capturing an important dynamic missing from the earlier models in the relevant literature.

First, we have analyzed subgame perfect Nash equilibrium in a two-period version of the contest. We have shown that players exert the same equilibrium efforts independent of the asymmetry in their effectiveness levels in a given period. The equilibrium investments depend on the asymmetry in the education efficiency. Second, we have analyzed open-loop equilibrium in an infinite-horizon version of the contest. The steady state efforts have similar characteristics with the equilibrium efforts in the two-period version. Interestingly, the steady state investments turn out to be symmetric as well, independent of any asymmetry in the model, whereas the asymmetry in the education efficiency significantly affects the steady state human capitals. Our results highlight the importance of investment on human capital in dynamic conflict situations.

\footnotetext{
${ }^{9}$ The only difference is that in the two-period model, there is an additional condition regulating the comparative statics on $\gamma_{i}$ 's.
} 


\section{References}

Alptekin, A. and P. Levine (2012). Military Expenditure and Economic Growth: A Meta-analysis. European Journal of Political Economy 28(4), 636-650.

Amegashie, J. A. (2011). Incomplete Property Rights and Overinvestment. Social Choice and Welfare $37,81-95$.

Barro, R. J. (2001). Human Capital and Growth. The American Economic Review 91(2), 12-17.

Becker, G. S. (1962). Investment in Human Capital: A Theoretical Analysis. Journal of Political Economy 70(5, Part 2), 9-49.

Ben-Porath, Y. (1967). The Production of Human Capital and the Life Cycle of Earnings. Journal of Political Economy, 352-365.

Bevia, C. and L. C. Corchón (2013). Endogenous Strength in Conflicts. International Journal of Industrial Organization 31, 297-306.

Black, S. E. and L. M. Lynch (1996). Human-capital Investments and Productivity. The American Economic Review 86(2), 263-267.

Clark, D. J. and T. Nilssen (2013). Learning by Doing in Contests. Public Choice 156, 329-343.

Clark, D. J. and C. Riis (1998). Contest Success Functions: An Extension. Economic Theory 11(1), 201-204.

Corchón, L. C. (2007). The theory of contests: A survey. Review of Economic Design 11(2), 69-100.

Dearden, L., H. Reed, and J. Van Reenen (2006). The Impact of Training on Productivity and Wages: Evidence from British Panel Data. Oxford Bulletin of Economics and Statistics 68(4), 397-421.

Dechenaux, E., D. Kovenock, and R. M. Sheremeta (2015). A Survey of Experimental Research on Contests, All-pay Auctions and Tournaments. Experimental Economics 18(4), 609-669.

Deger, S. and R. Smith (1983). Military Expenditure and Growth in Less Developed Countries. Journal of Conflict Resolution 27(2), 335-353.

Doğan, S., E. Karagözoğlu, K. Keskin, and Ç. Sağlam (2017). Multi-player Race. Working paper Bilkent University.

Engelbrecht, H.-J. (1997). International R\&D Spillovers, Human Capital and Productivity in OECD Economies: An Empirical Investigation. European Economic Review 41(8), 1479-1488.

Fu, Q. and J. Lu (2009). Contest with Pre-contest Investment. Economics Letters 103, 142-145.

Galor, O. and D. N. Weil (2000). Population, Technology, and Growth: From Malthusian Stagnation to the Demographic Transition and Beyond. The American Economic Review 90(4), 806-828.

Gradstein, M. (1998). Optimal Contest Design: Volume and Timing of Rent Seeking in Contests. European Journal of Political Economy 14, 575-585.

Gradstein, M. and K. A. Konrad (1999). Orchestrating Rent Seeking Contests. The Economic Journal 109, 536-545. 
Grossmann, M. and H. Dietl (2009). Investment Behaviour in a Two Period Contest Model. Journal of Institutional and Theoretical Economics 165, 401-417.

Grossmann, M., H. Dietl, and M. Lang (2010). Revenue Sharing and Competitive Balance in a Dynamic Contest Model. Review of Industrial Organization 36, 17-36.

Grossmann, M., M. Lang, and H. Dietl (2011). Transitional Dynamics in a Tullock Contest with a General Cost Function. The BE Journal of Theoretical Economics 11, Art. 17.

Huggett, M., G. Ventura, and A. Yaron (2006). Human Capital and Earnings Distribution Dynamics. Journal of Monetary Economics 53(2), 265-290.

Keskin, K. and Ç. Sağlam (2017). A Territorial Conflict: Trade-offs and Strategies. Forthcoming in Defence and Peace Economics.

Kollias, C. G. (1996). The Greek - Turkish Conflict and Greek Military Expenditure 1960-92. Journal of Peace Research 33(2), 217-228.

Konrad, K. A. (2009). Strategy and Dynamics in Contests. Oxford, UK: Oxford University Press.

Konrad, K. A. and K. Kovenock (2009). Multi-battle Contests. Games and Economic Behavior 66, $256-274$.

Le Van, C. and R.-A. Dana (2003). Dynamic Programming in Economics. Boston, MA: Kluwer Academic Publishers.

Leininger, W. and C. L. Yang (1994). Dynamic Rent-seeking Games. Games and Economic Behavior 7, 406-427.

Mankiw, N. G., D. Romer, and D. N. Weil (1992). A Contribution to the Empirics of Economic Growth. The Quarterly Journal of Economics 107(2), 407-437.

Mincer, J. (1958). Investment in Human Capital and Personal Income Distribution. Journal of Political Economy 66(4), 281-302.

Mincer, J. (1997). The Production of Human Capital and the Life Cycle of Earnings: Variations on a Theme. Journal of Labor Economics 15(1), S26-47.

Münster, J. (2007). Contests with Investment. Managerial and Decision Economics 28, 849-862.

Pieroni, L. (2009). Military Expenditure and Economic Growth. Defence and Peace Economics 20(4), $327-339$.

Rothschild, K. W. (1973). Military Expenditure, Exports and Growth. Kyklos 26(4), 804-814.

Schultz, T. W. (1961). Investment in Human Capital. The American Economic Review 51(1), 1-17.

Stokey, N. and R. Lucas (1989). Recursive Methods in Economic Dynamics (with E. Prescott). Cambridge, MA: Harvard University Press.

Yildirim, H. (2005). Contests with Multiple Rounds. Games and Economic Behavior 51, 213-227. 


\section{Appendix}

In this Appendix we provide the stability analysis. For each $i \in\{1,2\}$, the human capital constraint is

$$
h_{i, t+1}=(1-\delta) h_{i, t}+\gamma_{i} s_{i, t}^{\alpha}
$$

and our Euler equation can be re-written as

$$
s_{i, t+1}=\left(\frac{1}{\beta(1-\delta)} s_{i, t}^{1-\alpha}-\frac{\alpha \gamma_{i} V}{1-\delta} \cdot \frac{(1-\delta) h_{j, t}+\gamma_{j} s_{j, t}{ }^{\alpha}}{\left[(1-\delta)\left(h_{1, t}+h_{2, t}\right)+\gamma_{1} s_{1, t}{ }^{\alpha}+\gamma_{2} s_{2, t}{ }^{\alpha}\right]^{2}}\right)^{\frac{1}{1-\alpha}} \text {. }
$$

Taking the derivatives with respect to $s_{i, t}, s_{j, t}, h_{i, t}$, and $h_{j, t}$ yields

$$
\begin{aligned}
& \frac{\partial s_{i, t+1}}{\partial s_{i, t}}=\frac{1}{1-\alpha} s_{i, t+1}{ }^{\frac{\alpha}{1-\alpha}} \cdot\left(\frac{1-\alpha}{\beta(1-\delta)} s_{i, t}^{-\alpha}\right. \\
& \left.+\frac{2 \alpha^{2} \gamma_{i}^{2} V}{1-\delta} s_{i, t}^{\alpha-1} \frac{(1-\delta) h_{j, t}+\gamma_{j} s_{j, t}{ }^{\alpha}}{\left[(1-\delta)\left(h_{1, t}+h_{2, t}\right)+\gamma_{1} s_{1, t}{ }^{\alpha}+\gamma_{2} s_{2, t}{ }^{\alpha 3}\right]^{3}}\right) \\
& \frac{\partial s_{i, t+1}}{\partial s_{j, t}}=\frac{1}{1-\alpha} s_{i, t+1}{ }^{\frac{\alpha}{1-\alpha}} \cdot\left(\frac{\alpha^{2} \gamma_{i} \gamma_{j} V}{1-\delta} s_{j, t}{ }^{\alpha-1} \frac{(1-\delta)\left(h_{j, t}-h_{i, t}\right)+\gamma_{j} s_{j, t}^{\alpha}-\gamma_{i} s_{i, t}^{\alpha}}{\left[(1-\delta)\left(h_{1, t}+h_{2, t}\right)+\gamma_{1} s_{1, t}{ }^{\alpha}+\gamma_{2} s_{2, t}\right]^{3}}\right) \\
& \frac{\partial s_{i, t+1}}{\partial h_{i, t}}=\frac{1}{1-\alpha} s_{i, t+1}{ }^{\frac{\alpha}{1-\alpha}} \cdot\left(2 \alpha \gamma_{i} V \frac{(1-\delta) h_{j, t}+\gamma_{j} s_{j, t}{ }^{\alpha}}{\left[(1-\delta)\left(h_{1, t}+h_{2, t}\right)+\gamma_{1} s_{1, t}{ }^{\alpha}+\gamma_{2} s_{2, t}{ }^{\alpha}\right]^{3}}\right)
\end{aligned}
$$

and

$$
\frac{\partial s_{i, t+1}}{\partial h_{j, t}}=\frac{1}{1-\alpha} s_{i, t+1}{ }^{\frac{\alpha}{1-\alpha}} \cdot\left(\alpha \gamma_{i} V \frac{(1-\delta)\left(h_{j, t}-h_{i, t}\right)+\gamma_{j} s_{j, t}^{\alpha}-\gamma_{i} s_{i, t}^{\alpha}}{\left[(1-\delta)\left(h_{1, t}+h_{2, t}\right)+\gamma_{1} s_{1, t}{ }^{\alpha}+\gamma_{2} s_{2, t}\right]^{3}}\right) .
$$

Recall that at the steady state

$$
s_{i}=s_{j}=s
$$

and

$$
h_{i}=\frac{\gamma_{i}}{\delta} s^{\alpha} \quad \text { and } \quad h_{j}=\frac{\gamma_{j}}{\delta} s^{\alpha} .
$$

Thus we have

$$
\begin{aligned}
& (1-\delta)\left(h_{i}+h_{j}\right)+\gamma_{i} s_{i}{ }^{\alpha}+\gamma_{j} s_{j}{ }^{\alpha}=\frac{\gamma_{i}+\gamma_{j}}{\delta} s^{\alpha} \\
& (1-\delta)\left(h_{i}-h_{j}\right)+\gamma_{i} s_{i}{ }^{\alpha}-\gamma_{j} s_{j}{ }^{\alpha}=\frac{\gamma_{i}-\gamma_{j}}{\delta} s^{\alpha} .
\end{aligned}
$$

Recall also that

$$
s=\frac{\alpha \beta \delta \gamma_{1} \gamma_{2} V}{\left(\gamma_{1}+\gamma_{2}\right)^{2}(1-\beta(1-\delta))}
$$


We then obtain

$$
\begin{gathered}
\left.\frac{\partial s_{i, t+1}}{\partial s_{i, t}}\right|_{S S}=\frac{(1-\alpha)\left(\gamma_{1}+\gamma_{2}\right)+2 \alpha \delta \gamma_{i}(1-\beta(1-\delta))}{\beta(1-\delta)(1-\alpha)\left(\gamma_{1}+\gamma_{2}\right)}\left(\frac{\alpha \beta \delta \gamma_{1} \gamma_{2} V}{\left(\gamma_{1}+\gamma_{2}\right)^{2}(1-\beta(1-\delta))}\right)^{\frac{\alpha^{2}}{1-\alpha}} \\
\left.\frac{\partial s_{i, t+1}}{\partial s_{j, t}}\right|_{S S}=\frac{\alpha \delta\left(\gamma_{j}-\gamma_{i}\right)(1-\beta(1-\delta))}{\beta(1-\delta)(1-\alpha)\left(\gamma_{1}+\gamma_{2}\right)}\left(\frac{\alpha \beta \delta \gamma_{1} \gamma_{2} V}{\left(\gamma_{1}+\gamma_{2}\right)^{2}(1-\beta(1-\delta))}\right)^{\frac{\alpha^{2}}{1-\alpha}} \\
\left.\frac{\partial s_{i, t+1}}{\partial h_{i, t}}\right|_{S S}=\frac{2 \alpha \delta^{2} \gamma_{i} \gamma_{j} V}{(1-\alpha)\left(\gamma_{1}+\gamma_{2}\right)^{3}}\left(\frac{\alpha \beta \delta \gamma_{1} \gamma_{2} V}{\left(\gamma_{1}+\gamma_{2}\right)^{2}(1-\beta(1-\delta))}\right)^{\frac{2 \alpha^{2}-\alpha}{1-\alpha}}
\end{gathered}
$$

and

$$
\left.\frac{\partial s_{i, t+1}}{\partial h_{j, t}}\right|_{S S}=\frac{\alpha \delta^{2} \gamma_{i}\left(\gamma_{j}-\gamma_{i}\right) V}{(1-\alpha)\left(\gamma_{1}+\gamma_{2}\right)^{3}}\left(\frac{\alpha \beta \delta \gamma_{1} \gamma_{2} V}{\left(\gamma_{1}+\gamma_{2}\right)^{2}(1-\beta(1-\delta))}\right)^{\frac{2 \alpha^{2}-\alpha}{1-\alpha}}
$$

The respective Jacobian matrix is

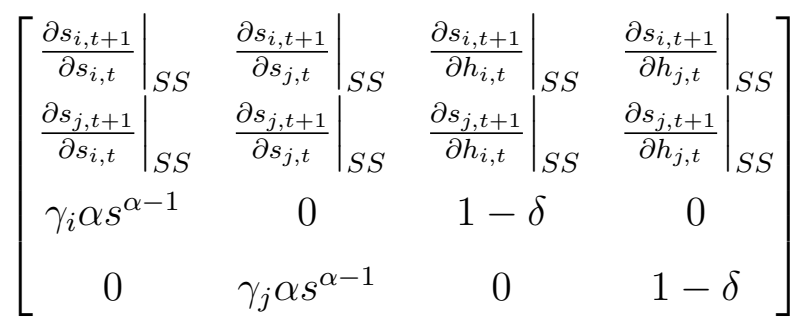

where the first row consists of the equations above; the second row consists of the symmetrics of those equations; and the third and fourth row consist of the derivatives of $h_{i, t+1}$ and $h_{j, t+1}$ with respect to the corresponding parameters, respectively.

Then, we need to find the eigenvalues of this matrix in order to complete our stability analysis. Letting

$$
\begin{aligned}
x & =\frac{1-\alpha(1-\delta)(1+\beta \delta)}{(1-\alpha)(1-\delta)}, \\
y & =\frac{1}{\beta}\left(\frac{\alpha \beta \delta \gamma_{1} \gamma_{2} V}{\left(\gamma_{1}+\gamma_{2}\right)^{2}(1-\beta(1-\delta))}\right)^{\frac{\alpha^{2}}{1-\alpha}}, \text { and } \\
z & =\frac{1-\delta+x y}{2}
\end{aligned}
$$

we can write the eigenvalues as follows:

$$
\begin{aligned}
& \mu_{1}=\mu_{2}=z-\sqrt{z^{2}-y}, \\
& \mu_{3}=\mu_{4}=z+\sqrt{z^{2}-y} .
\end{aligned}
$$


Here we see that $x>1+\delta$ and $y>0$, so that $z>0$. As a result, the roots can not be repeated complex conjugates since

$$
z^{2}-y=\frac{(x y)^{2}+(2(1-\delta) x-4) y+(1-\delta)^{2}}{4} \geq 0 .
$$

This stems from the fact that the roots of the quadratic equation

$$
(x y)^{2}+(2(1-\delta) x-4) y+(1-\delta)^{2}=0
$$

are complex conjugates, since its discriminant is negative:

$$
\begin{aligned}
(2(1-\delta) x-4)^{2}-4(x(1-\delta))^{2} & =16(1-(1-\delta) x) \\
& =-\frac{16(1-\beta(1-\delta)) \alpha \delta}{1-\alpha}<0
\end{aligned}
$$

By the equations (31) and (32), we have

$$
\begin{aligned}
\mu_{i}+\mu_{j} & =2 z>0, \\
\mu_{i} \cdot \mu_{j} & =y>0,
\end{aligned}
$$

for every $i \in\{1,2\}$ and $j \in\{3,4\}$. This leads to monotonic convergence as

$$
\begin{aligned}
& \mu_{1}=\mu_{2}>0 \\
& \mu_{3}=\mu_{4}>0 .
\end{aligned}
$$

As the dynamics are governed by the placement of the two sets of repeated roots on the real line, the parameter combinations which qualitatively change the stability properties of the dynamic system should be analyzed in more detail. To do so, we need to focus on the parameter values under which unit eigenvalues are obtained. The following table summarizes the possible cases:

$$
\begin{array}{ccc}
(i) & (\text { ii }) & (\text { iii }) \\
z^{2}=y & z^{2}>y & z^{2}>y \\
y=1 & y=2 z-1 & y=2 z-1 \\
z=1 & z>1 & z<1 \\
\mu_{1,2}=1 & \mu_{1,2}=1 & \mu_{1,2}<1 \\
\mu_{3,4}=1 & \mu_{3,4}>1 & \mu_{3,4}=1
\end{array}
$$

Case (i) requires that $z^{2}=y=1$; but this would imply that $x=1+\delta$ which contradicts with $x>1+\delta$. Thus, case (i) cannot occur.

Note that if $y=2 z-1$, then we have either $\mu_{1,2}=1$ or $\mu_{3,4}=1$ depending on whether $z>1$ or $z<1$, respectively. We have $y=2 z-1$ if and only if

$$
V=V_{C} \equiv \frac{\left(\gamma_{1}+\gamma_{2}\right)^{2}}{\gamma_{1} \gamma_{2}} \frac{(1-\beta(1-\delta))}{\alpha \beta \delta}\left(\frac{(1-\alpha) \beta(1-\delta)}{1-\alpha \beta(1-\delta)}\right)^{\frac{1-\alpha}{\alpha^{2}}}
$$


Furthermore, $z=1$ if and only if

$$
V=V_{Z} \equiv \frac{\left(\gamma_{1}+\gamma_{2}\right)^{2}}{\gamma_{1} \gamma_{2}} \frac{(1-\beta(1-\delta))}{\alpha \beta \delta}\left(\frac{(1-\alpha) \beta\left(1-\delta^{2}\right)}{1-\alpha(1-\delta)(1+\beta \delta)}\right)^{\frac{1-\alpha}{\alpha^{2}}}
$$

Note that $V_{C}<V_{Z}$ since the parameters $\alpha, \beta$, and $\delta$ are less than one.

Case (ii) cannot occur as $V=V_{C}$ implies that $V<V_{Z}$, i.e., $z<1$.

Case (iii) is the only possibility that remains.

These reveal that the steady state cannot be a "source". The steady state is either "saddle-path stable" or a "sink" depending on the value of the winning prize $V$. Indeed, there exists a critical value for the winning prize above which a multiplicity of equilibrium paths emerges. The dynamics of the system around the unique steady state exhibits local indeterminacy (i.e., $\mu_{1,2}<\mu_{3,4}<1$ ) if $V<V_{C}$. Moreover, as soon as $V>V_{C}$, the unique steady state turns out to be saddle-path stable (i.e., $\mu_{1,2}<1<\mu_{3,4}$ ). Figure 2 summarizes these dynamics for the following parameter values: $\beta=0.95, \delta=0.25$, $\alpha=0.5$, and $\gamma_{1}=\gamma_{2}=2$.

\section{[Figure 2]}

The analysis above takes $V$ into consideration as the bifurcation parameter. To provide a further understanding of our model, in the following we normalize $\gamma_{2}=1$ and concentrate on $\gamma_{1}$ as the bifurcation parameter. Once again, among the three cases specified above, only Case (iii) occurs. Then there exist two critical values $\gamma_{1}^{-}$and $\gamma_{1}^{+}$ such that the unique steady state is saddle-path stable when $\gamma_{1}^{-}<\gamma_{1}<\gamma_{1}^{+}$. Otherwise, we observe local indeterminacy. These critical values solve $\mu_{3,4}=1$ by definition, and they are given by

$$
\gamma_{1}^{+}=\frac{1+\sqrt{1-\frac{4(1+\beta(1-\delta))\left(\frac{(1-\alpha) \beta(1-\delta)}{1-\alpha \beta(1-\delta)}\right)^{\frac{1-\alpha}{\alpha^{2}}}}{\alpha \beta \delta V}}}{1-\sqrt{1-\frac{4(1+\beta(1-\delta))\left(\frac{(1-\alpha) \beta(1-\delta)}{1-\alpha \beta(1-\delta)}\right)^{\frac{1-\alpha}{\alpha^{2}}}}{\alpha \beta \delta V}}} \text { and } \gamma_{1}^{-}=\frac{1-\sqrt{1-\frac{4(1+\beta(1-\delta))\left(\frac{(1-\alpha) \beta(1-\delta)}{1-\alpha \beta(1-\delta)}\right)^{\frac{1-\alpha}{\alpha^{2}}}}{\alpha \beta \delta V}}}{1+\sqrt{1-\frac{4(1+\beta(1-\delta))\left(\frac{(1-\alpha) \beta(1-\delta)}{1-\alpha \beta(1-\delta)}\right)^{\frac{1-\alpha}{\alpha^{2}}}}{\alpha \beta \delta V}}}
$$

Notice that $\gamma_{1}^{+}=1 / \gamma_{1}^{-}$. This further implies that the unique steady state turns out to be saddle-path stable if the asymmetry between players' effectiveness parameters is sufficiently low. However, when one of the players is too dominant in terms of effectiveness, the unique steady state exhibits local indeterminacy. Figure 3 summarizes these dynamics for the following parameter values: $\beta=0.95, \delta=0.25, \alpha=0.5$, and $V=8$.

\section{[Figure 3]}


We should also note that for given values of $\alpha, \beta$, and $\delta$, there exists a critical value for the winning prize below which a solution for $\mu_{3,4}=1$ does not exist. In such cases, we always have local indeterminacy.

Finally, as for the speed of convergence, we can note that the properties of the dynamics depend on the stable eigenvalue $\mu_{s} \equiv \mu_{1,2} \in(0,1)$ such that a higher value of $\mu_{s}$ would imply a slower convergence to the steady state. Accordingly, in contrast to Grossmann et al. (2010)'s results that linear costs imply immediate convergence of the asset stocks to the steady state and the convexity of cost functions influence the speed of convergence, we find that even with linear cost functions, non-immediate convergence is possible. Obviously, the speed of convergence depends on multiple model parameters. For concrete examples, given the parameter values used in Figure 2, the speed of convergence decreases as $V$ increases; and given the parameter values used in Figure 3, the speed of convergence first decreases but then increases as $\gamma_{1}$ increases. 


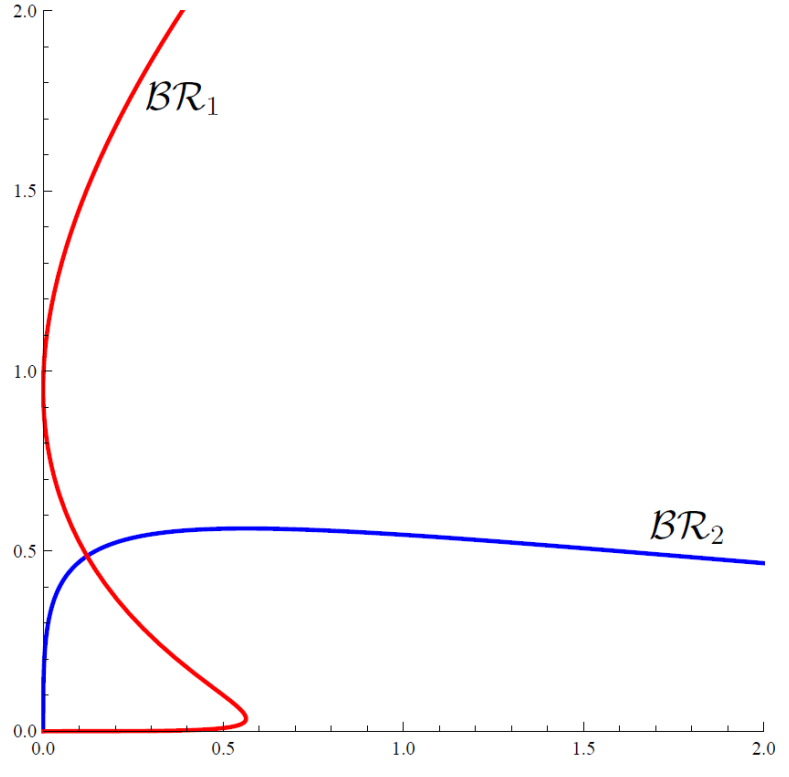

(a) $h_{1,1}=2, \gamma_{1}=1$

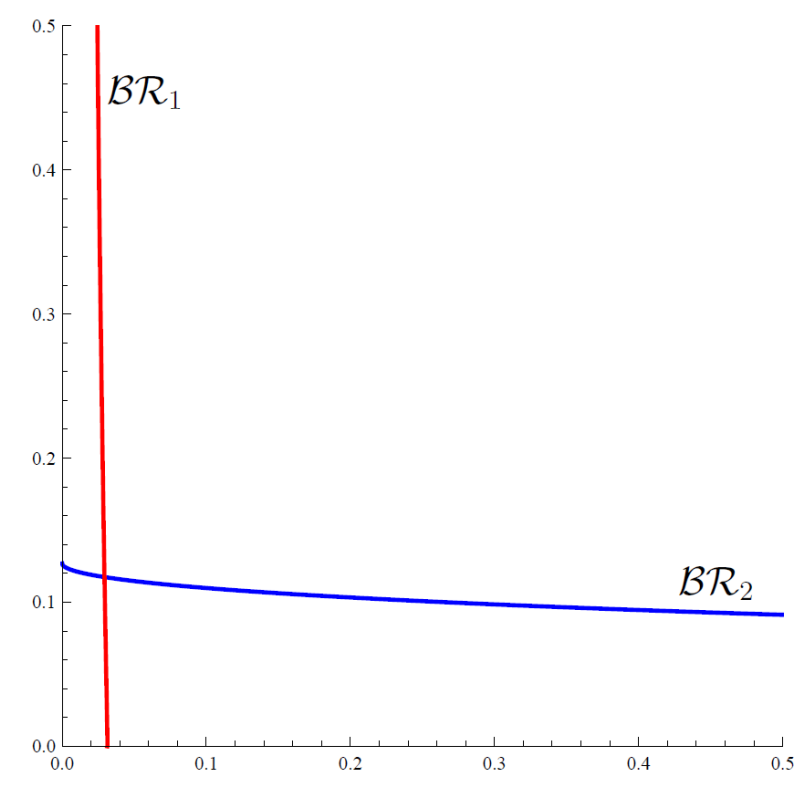

(c) $h_{1,1}=4, \gamma_{1}=1$

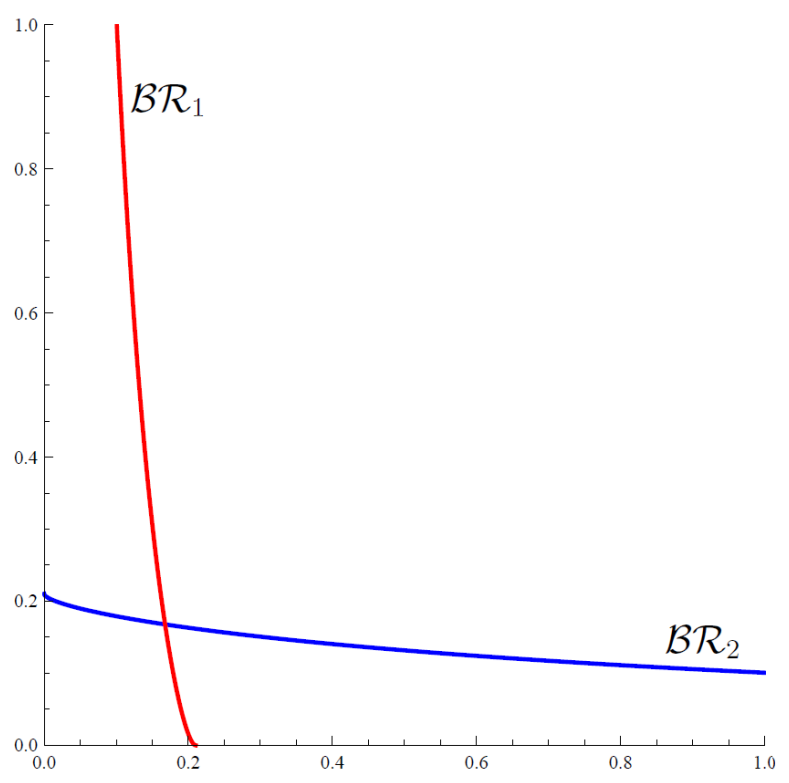

(b) $h_{1,1}=2, \gamma_{1}=2$

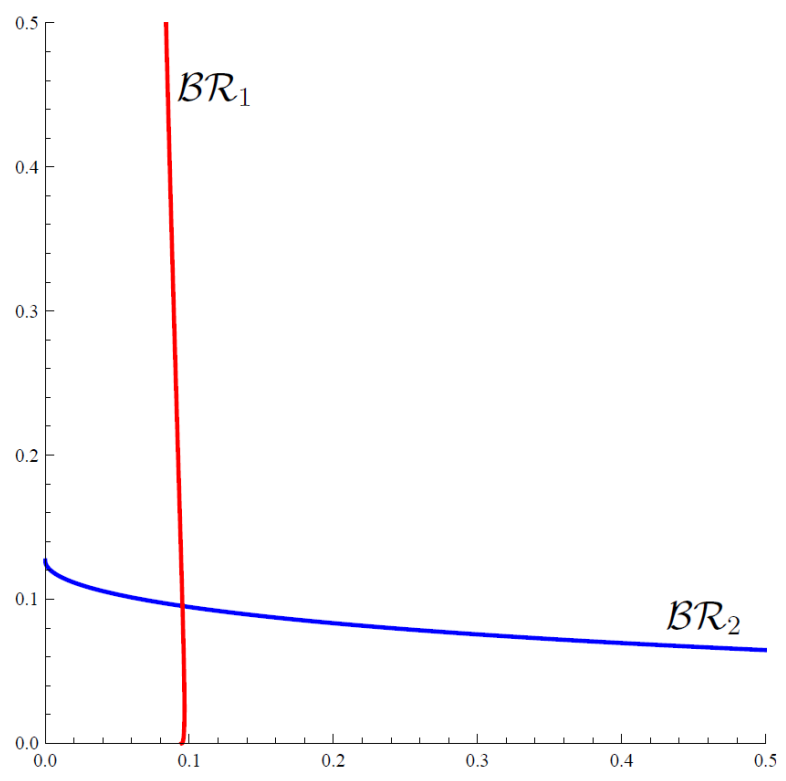

(d) $h_{1,1}=4, \gamma_{1}=2$

Figure 1: Best Response Functions and the Corresponding Equilibrium Investment Levels in Period 1 under the Given Values of Model Parameters 


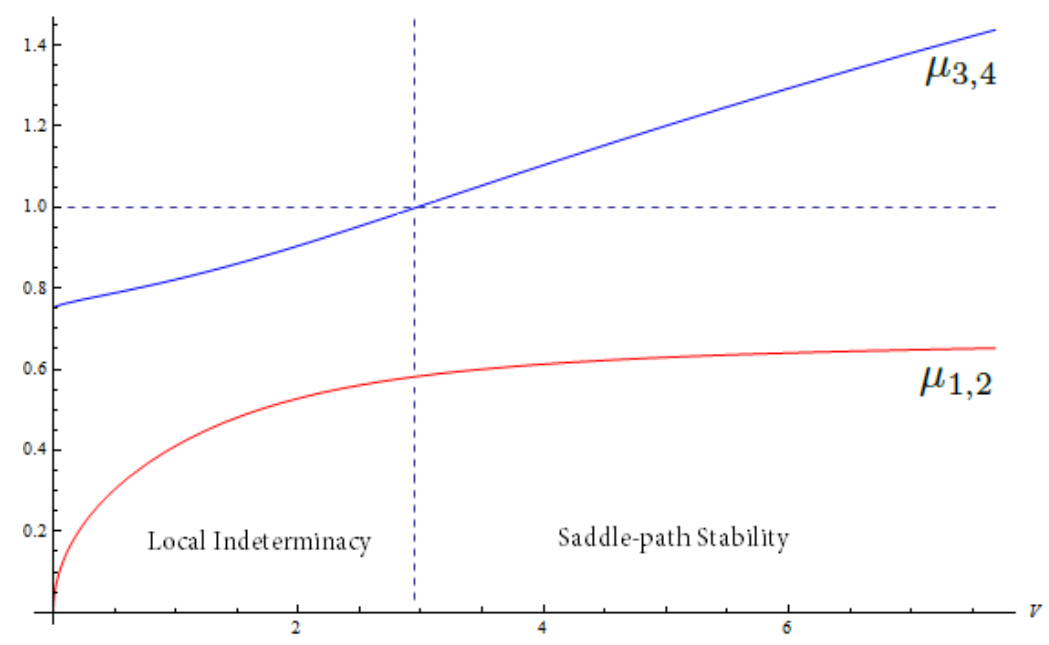

Figure 2: Eigenvalues under the Given Values of Model Parameters ( $V$ is the Bifurcation Parameter)

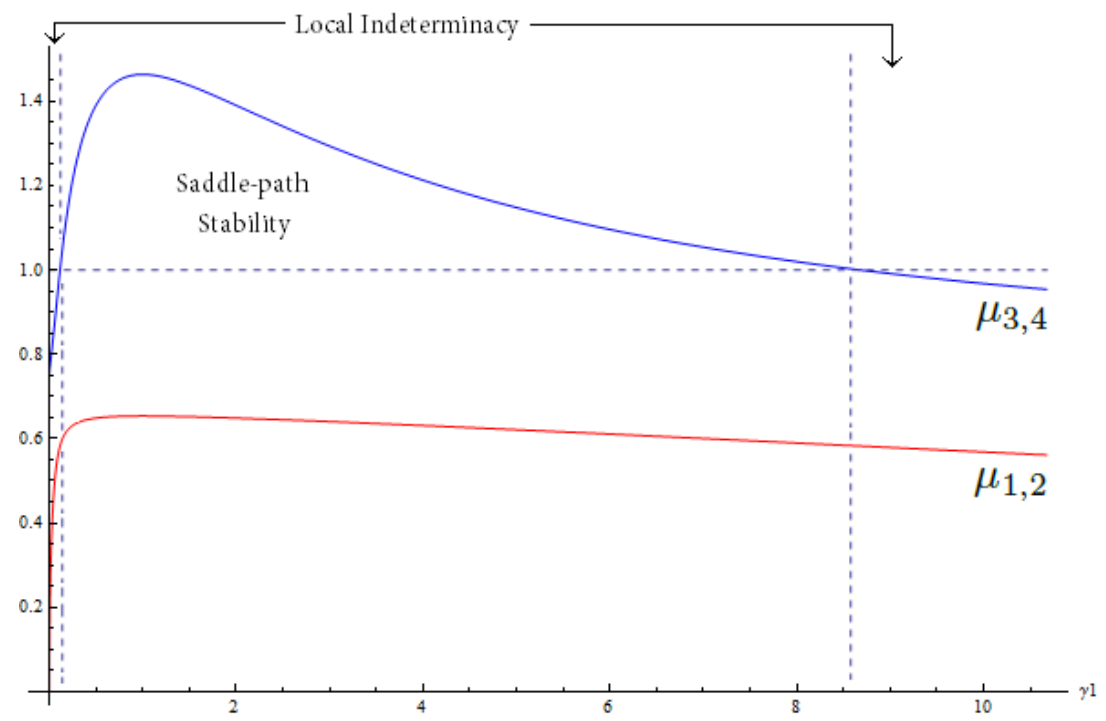

Figure 3: Eigenvalues under the Given Values of Model Parameters ( $\gamma_{1}$ is the Bifurcation Parameter) 